\title{
IGUALDADE SUBSTANCIAL E AUTONOMIA PRIVADA NO CÓDIGO CIVIL BRASILEIRO DE 2002
}

Roxana Cardoso Brasileiro Borges

Doutora em Direito das Relações Sociais (Direito Civil) pela Pontifícia Universidade Católica de São Paulo (PUC/SP-2003), Mestre em Instituições Jurídico -Políticas (Direito Ambiental e Civil) pela Universidade Federal de Santa Catarina (UFSC-1999), Bacharela em Direito pela Universidade Católica do Salvador (UCSal - 1996), Professora Associada de Direito Civil na Faculdade de Direito da Universidade Federal da Bahia, onde leciona no Doutorado, no Mestrado e na Graduação, Professora Adjunta na Faculdade de Direito da Universidade do Estado da Bahia, Professora no Centro Universitário Estácio da Bahia (Estácio Fib), atua nas áreas de Direito Civil, Direito Ambiental, Metodologia da Pesquisa e Bioética e Biodireito.

\section{EMANuel Lins Freire Vasconcellos}

Aluno do Doutorado em Direito e Mestre em Direito (2012) pelo Programa de Pós-Graduação em Direito da Universidade Federal da Bahia. Professor substituto de Direito Civil da Faculdade de Direito da UFBA. Coordenador Acadêmico do curso de Direito e Professor de Direito Civil da Faculdade Ruy Barbosa (campus Paralela). Advogado.

\section{Resumo}

Sob o influxo da corrente doutrinária que propugna a constitucionalização do Direito Civil, ampliou-se a discussão sobre a função promocional do Código Civil de 2002 no que diz respeito à igualdade substancial. Neste trabalho, busca-se analisar os instrumentos oferecidos pelo novel codificação para a efetivação da aludida igualdade, em contraposição à proteção da igualdade formal erigida pelas codificaçôes oitocentistas e, no Brasil, pelo Código Civil de 1916. Situado historicamente em um período de afirmação de direitos prestacionais e construído com base em diretrizes distintas da codificação brasileira de 1916, o novo Diploma Civil pátrio apresenta, mesmo que de forma tímida e insuficiente, instrumentos idôneos à concretização da aludida igualdade substancial, que se encontram esquecidos por expressivo contingente doutrinário em virtude da valorização em demasia do fenômeno chamado constitucionalização do direito.

\section{Palavras-chave}

Autonomia privada; Igualdade substancial; Constitucionalização do direito; Sincretismo metodológico; Defeitos do negócio jurídico. 


\section{Abstract}

Under the influence of doctrinal current that advocates the constitutionalizsation of civil law, expanded the discussion on the promotional role of the Civil Code of 2002 with regard to substantive equality. In this paper, we try to analyze the instruments offered by the novel encoding for the realization of the aforementioned equality, as opposed to the protection of formal equality erected by the nineteenth-century encodings, and in Brazil, the Civil Code of 1916. Located historically in a statement period prestacionais rights and built based on different coding guidelines of the Brazilian 1916, the new Civil Diploma features, even if timid and insufficient, suitable instruments to the achievement of the aforementioned substantive equality, which are forgotten by significant doctrinal contingent because of valuation in excess of the phenomenon called constitutionalization of law.

\section{Key words}

Civil autonomy; Substantial equality; Constitutionalization of law; Methodological syncretism; Legal addictions.

\section{Introdução}

O projeto oitocentista de realização da igualdade por intermédio da liberdade econômica revelou-se frustrado pela história, que viu o liberalismo econômico acentuar a concentração de riqueza nos países ocidentais. Como consequência, o Direito Civil passou por profunda reformulaçáo com o advento do Estado Social, decorrente especialmente da constitucionalização do direito e da intervenção crescente do Estado na esfera privada. A liberdade econômica sofreu expressiva limitação, ao tempo que os institutos jurídicos do Direito Civil passaram a ser interpretados em conformidade com a Constituição.

Partindo desse pressuposto, tomou corpo a doutrina do que se convencionou denominar de Direito Civil-Constitucional, que pôe acento na questão da igualdade substancial no âmbito do Direito Civil, em contraposição à igualdade formal de outrora.

Essa construção doutrinária, naturalmente, não está imune a críticas. Considerável parcela da doutrina civilista se insurge contra os excessos do Direito Civil Constitucional, tendo por base, essencialmente, a crítica ao sincretismo metodológico, ao uso indistinto de instrumentos nem sempre compatíveis com o Direito Civil e ao abandono dos institutos civis para a solução de conflitos da contemporaneidade.

Assim, expressa-se a importância de se considerar as peculiaridades do Direito Privado (e, em especial, do Direito Civil), que não podem ser ignoradas em função do fenômeno da constitucionalização, posto que a Constituição Federal, malgrado figure, na condição 
de vértice do sistema jurídico, como ponto de partida para a interpretação do Direito Civil, não possui o condão de anular os institutos jurídicos próprios do Direito Privado.

O presente paper surge, portanto, de um conjunto de reflexôes que parte das contribuições teóricas já desenvolvidas pelo campo do Direito Civil Constitucional referentes ao tema da igualdade substancial e a sua relação com a autonomia privada, mas reconhece a pertinência das críticas ao excesso desse campo de pensamento ${ }^{1}$, especialmente no que se refere ao sincretismo metodológico e ao abandono das soluçóes oferecidas pela própria codificação civil para a solução de problemas que envolvam algum grau de desigualdade fática.

Deste modo, este artigo intenta analisar especificamente a relação entre autonomia privada e igualdade substancial no Código Civil brasileiro de 2002 (CCB), analisando os instrumentos oferecidos por este diploma legal para a concretizaçáo da igualdade substancial.

Neste sentido, o primeiro capítulo é dedicado a uma breve exposição da dicotomia público-privado, mormente para se contextualizar as contribuiçōes do Direito Civil Constitucional e as críticas tecidas pelo campo que se autodenomina Direito Civil Contemporâneo.

O segundo capítulo trata da autonomia privada e da liberdade no Direito Civil, partindo de uma breve mençáo ao projeto oitocentista de autonomia da vontade para chegar à concepção atual de autonomia privada.

O terceiro capítulo tem por objeto a análise do princípio da igualdade substancial no paradigma teórico do Direito Civil Constitucional. Mesmo sem adentrar especificamente nas diferentes teorias sobre a eficácia horizontal dos direitos fundamentais (o que escaparia ao objetivo do presente artigo), parte-se da premissa que o elemento teórico essencial para a concretização do princípio da igualdade substancial neste campo de pensamento é a aplicação direta dos direitos fundamentais nas relações privadas, culminando por desprivilegiar ou, até mesmo, abandonar os institutos próprios do Direito Civil idôneos à concretização da aludida igualdade.

O quarto capítulo traz, por conseguinte, as críticas ao Direito Civil Constitucional que, no que alude particularmente à igualdade substancial, parecem mais vigorosas. Neste sentido, privilegia-se a identificação da análise interna e externa do Direito (ou do fenômeno jurídico), verificando-se que a interpretação do Direito Civil a partir de instrumentos e

1 As críticas apresentadas no presente paper sustentam-se, basicamente, nas formulaçóes do Professor Otávio Luiz Rodrigues Junior, que organiza, juntamente com outros civilistas, a Rede de Pesquisa de Direito Civil Contemporâneo. Neste sentido, cf. <www.direitocivilcontemporaneo.com>, <www. direitocontemporaneo.com $>$ e <www.conjur.com.br/secoes/colunas/direito-civil-atual $>$. 
institutos próprios da codificação brasileira de 2002 não prescinde de valores e mesmo de uma análise econômica incipiente, mas, isto sim, localiza estes elementos como externos ao fenômeno jurídico.

Por fim, o último capítulo dedica-se a tecer uma breve e ilustrativa análise - não se pretenderia esgotar o assunto nas escassas linhas do presente paper - de alguns institutos próprios do Código Civil de 2002, relacionando-os com os princípios da igualdade e da autonomia privada.

\section{A Dicotomia Público-Privado}

No campo jurídico e político, é corriqueira a distinção entre público e privado. Dentre os vários critérios possíveis para se efetuar a distinção, a ideia mais básica, no Direito, é aquela segundo a qual o direito público seria aquele destinado a regular as relaçóes entre o Estado e os cidadãos, ou entre os próprios entes estatais; o direito privado, por seu turno, constituir-se-se na regulamentação das relaçóes estabelecidas entre particulares.

Sobre o tema, Bobbio (2011) estabelece uma delicada confluência de disciplinas direito, ciência política, filosofia e história das ideias - para apresentar teoricamente esta grande dicotomia que baliza o pensamento político-jurídico clássico e contemporâneo, cuja origem remonta a passagens do Corpus Iuris (Institutiones, I, I, 4; Digesto, I, I, I, 2), em que a dupla de termos público/privado fez seu ingresso na história do pensamento político e social do Ocidente.

O direito público e o privado constituíram, na Escola de Exegese, dois ramos estanques e rigidamente compartimentados (TEPEDINO, 2000). Na linguagem jurídica, a preeminência da distinção entre direito público e privado sobre todas as outras, a constância do uso nas diversas épocas históricas, a sua força inclusiva, foram tão expressivas que levaram Radbruch a considerar os conceitos de direito privado e de direito público inclusive como duas categorias apriorísticas do pensamento jurídico (BOBBIO, 2011).

Bobbio (2011) pontua que os dois termos de uma dicotomia podem ser definidos um independente do outro, ou então apenas um deles é definido e o outro ganha uma definição negativa (neste segundo caso, diz-se que o primeiro é o termo forte e o segundo o termo fraco). De acordo com o pensador italiano, a definição de direito público e privado é um exemplo do primeiro caso, mas dos dois termos o mais forte é o primeiro, na medida em que frequentemente de privado pode ser definido como não-público, raramente o contrário.

Ademais, os dois termos de uma dicotomia se condicionam reciprocamente, no sentido de que se reclamam continuamente um ao outro: na linguagem jurídica, a escritura pública remete imediatamente por contraste à escritura privada e vice-versa; na linguagem 
comum, o interesse público determina-se imediatamente em relação e em contraste com o interesse privado e vice-versa. No interior do espaço em que os dois termos se delimitam, a partir do momento em que este espaço é totalmente ocupado, eles, por sua vez, delimitam-se reciprocamente, no sentido de que a esfera do público chega até onde começa a esfera do privado e vice-versa. Um dos lugares-comuns do secular debate sobre a relaçáo entre a esfera do público e do privado é que, aumentando a esfera do público, diminui a do privado, sendo igualmente válido o contrário; uma constatação que é geralmente acompanhada e complicada por juízos de valor contrapostos.

De fato, a originária diferenciação entre o direito público e o privado é acompanhada pela afirmação da supremacia do primeiro sobre o segundo. Relevante doutrina, contudo, insurgiu-se contra a aprioristica supremacia do interesse público sobre o privado, de modo a inaugurar um novo marco na discussão do tema (SARMENTO, 2010; BARROSO, 2011).

Para Bobbio, a relevância conceitual e também classificatória - senão axiológica - da dicotomia público/privado está no fato de que ela compreende, ou nela convergem, outras dicotomias tradicionais e recorrentes nas ciências sociais, que a completam e podem inclusive substituí-la.

Nada obstante, ao longo dos séculos alternou-se o primado do público sobre o privado e o primado do privado sobre o público (FACCHINI NETO, 2010; BOBBIO, 2011), ao tempo que ocorre, simultaneamente, uma relativização da rígida dicotomia com os fenômenos da privatização do público e de uma paralela publicização do privado. Este último fenômeno se torna muito evidente com o que parte da doutrina jurídica convencionou denominar "constitucionalização do Direito Civil".

\section{0 Direito Civil Oitocentista e o Paradigma da Liberdade e da Autonomia Privada}

Dentre as flutuaçôes históricas em que o direito público ora prevalecia, ora não (quando predominava o direito privado), cumpre destacar o papel das codificaçóes produzidas no século XVIII. Neste período, o Direito Público passa a ser visto como o ramo do Direito que disciplina o Estado, ao tempo que o Direito Privado é tido como o ramo do Direito que disciplina a Sociedade Civil, marcando uma rígida separação entre ambos. As relaçóes privadas são estruturadas a partir de uma concepção de propriedade absoluta e de uma plena liberdade contratual (espaços que o Direito Público não deveria atingir), positivada em todos os Códigos Civis neste primeiro ciclo das codificaçóes. A característica central deste período histórico é que o direito se torna estatal (pois o legislador passa a se ocupar de forma sistemática e abrangente do Direito Privado) e burguês (pois o Direito Privado passa a espelhar a ideologia, os anseios e as necessidades da classe socioeconômica 
em ascensão em praticamente todos os Estados ocidentais (FACCHINI NETO, 2010, p. 41-2).

A autonomia da vontade (depois aperfeiçoada como autonomia privada) figurava como instituto central no Direito Civil estatal e burguês oitocentista, posto que essencial para viabilizar a livre aquisição e circulação de riquezas. Em uma ordem normativa que protegia, essencialmente, interesses patrimoniais, assegurar a liberdade de contratar e a igualdade formal de posições entre os figurantes de um negócio jurídico era premissa indispensável.

Nada obstante, não constitui tarefa fácil definir o que seria autonomia privada, como bem reconhece Pietro Perlingieri (2002, p. 17), que a conceitua da seguinte forma:

Querendo tentar uma definição inicial e considerando-a como mero ponto de partida para os sucessivos desenvolvimentos críticos, pode-se entender por "autonomia privada", em geral, o poder, reconhecido ou concedido pelo ordenamento estatal a um individuo ou a um grupo, de determinar vicissitudes jurídicas (...) como consequência de comportamentos - em qualquer medida - livremente assumidos. (grifos nossos)

Essa concepção viabiliza a liberdade de regular por si as próprias ações, permitindo aos indivíduos envolvidos em um comportamento comum determinar as regras daquele comportamento por meio de um acordo de vontades. Tal posiçáo, malgrado simbolize um quadro ideal e tenha uma quase ausência de realização histórica plena, exerceu importante influência no pensamento jurídico e na praxe, colocando-se como a marca do valor da liberdade individual (PERLINGIERI, 2002, p. 17).

Essa formulação, essencial no período do Estado Moderno ou Liberal, foi essencial à viabilização do liberalismo econômico, dando pouca ou nenhuma importância, no âmbito do Direito Civil, para o tema da igualdade (SARMENTO, 2008; PERLINGIERI, 2007; FACCHINI NETO, 2010). Daí ser corrente afirmar que, nesse período, prevalecia o "ter" em detrimento do "ser".

Segundo Ana Prata, a autonomia da vontade - geralmente utilizada como sinônimo de autonomia privada - pressupóe o poder que a vontade livremente expressa tem de criar, modificar e extinguir relaçóes jurídicas, dentro dos limites legais (1998, p. 113).

De forma criteriosa, Roxana Borges (2005) cuida de distinguir os conceitos de autonomia jurídica individual (faculdade de realizar condutas lícitas, posto não proibidas) e autonomia privada (liberdade negocial), diferenciando, em seguida, a concepçáo clássica de autonomia da vontade (vontade como fonte de direito) e autonomia privada (vontade lícita, ou conforme ao direito, como fonte criadora de relaçôes jurídicas). Essencial, para a autora, é conceber a possibilidade de exercício da autonomia privada em negócios jurídicos não contratuais, isto é, onde o objeto do negócio não tenha conteúdo patrimonial (pelo 
menos direto). A limitação à vontade onipotente (construção exacerbadamente individualista), constituindo barreiras jurídicas à liberdade negocial, é que justifica a importância da distinção entre autonomia da vontade e autonomia privada. Assim, a teoria da autonomia privada compreende o âmbito individual e o público (da competência normativa estatal, numa concepção estatista).

De fato, segundo Luigi Ferri (2001, p. 5), o problema central da autonomia privada reside nos seus limites, e não na importância exagerada que é - ou era - dada ao debate entre os defensores do dogma voluntarista contra aqueles que propugnam o dogma da declaração. A autonomia privada não é expressão de uma mera licitude ou faculdade, e sim a manifestaçáo de poder, e, precisamente, do poder de criar, dentro dos limites estabelecidos pela lei, normas juridicas (FERRI, 2001, p. 7).

Portanto, a autonomia privada, como evolução do dogma voluntarista, constituiu-se como um dos princípios fundamentais do sistema de Direito Privado, em um reconhecimento da existência de um âmbito particular de atuação do sujeito, com eficácia normativa. É parte do princípio de autodeterminação dos homens, é manifestação da subjetividade, o princípio dos tempos modernos que reconhece a liberdade individual e a autonomia do agir, segundo Hegel, que foi quem pela primeira vez a ele se referiu. Para esse filósofo, a subjetividade era a marca dos tempos modernos, em torno do que se desenvolveram os sistemas de Direito que tinham, naquela época, o indivíduo como eixo central — hoje a pessoa humana (AMARAL NETO, 1999).

Decerto que o modelo oitocentista de Direito Civil cumpriu um papel político essencial: a defesa dos interesses de uma classe socioeconômica em ascensão, que identificava no Estado um inimigo a ser contido através de um Direito Constitucional estruturado no liberalismo politico e no absenteísmo estatal, associado à ideia central da igualdade formal que caracterizava o liberalismo econômico do Estado Moderno/Liberal.

O advento do Estado do Bem-Estar Social, decorrente da crise do liberalismo econômico, contudo, colocou acento no Direito Constitucional, na intervenção econômica do Estado nas relaçóes privadas e no consequente dirigismo contratual, alterando profundamente os marcos teóricos do Direito Civil. Neste contexto, a igualdade substancial emerge como limite à autonomia privada, que fora considerada, no projeto oitocentista, como um paradigma intangível e inabalável.

\section{Direito Civil Constitucional: A Eficácia Horizontal dos Direitos Fundamen- tais e a Centralidade do Paradigma da Igualdade na Reconstrução do Di- reito Civil}

No pensamento que se convencionou chamar de Direito Civil Constitucional, foi fortalecida a ideia de que as normas constitucionais não teriam sentido apenas negativo 
(como limites ao legislador ordinário), mas possuiriam caráter transformador, passando a ser entendidas como fundamento conjunto de toda a disciplina normativa infraconstitucional, como já afirmava Maria Celina Bodin de Moraes (1991) antes mesmo do advento do Código Civil de 2002.

Neste contexto, seria inevitável a inflexão da disciplina civilista (voltada anteriormente para a tutela dos valores patrimoniais) em obediência aos enunciados constitucionais, os quais não mais admitem a proteção da propriedade e da empresa como bens em si, mas somente enquanto destinados a efetivar valores existenciais, realizadores da justiça social. Assim, qualquer norma ou cláusula negocial (campo privilegiado da autonomia privada), por mais insignificante que parecesse, deveria se coadunar e exprimir a normativa constitucional. Sob essa ótica, as normas do Direito Civil necessitariam ser interpretadas como reflexo das normas constitucionais - estas assumiriam a função de, no Direito Civil, validar a norma ordinária aplicável ao caso concreto, modificando os institutos tradicionais à luz dos valores e princípios constitucionais (BODIN DE MORAES, 1991).

Segundo este campo de pensamento, a rígida dicotomia entre Direito Público e Privado começa a se redefinir, gradativamente, na Europa do início do Século XX e no Brasil depois da década de 30, com a maciça intervenção do Estado na economia e com o processo, daí decorrente, de restrição à autonomia privada, associado ao fenômeno conhecido como dirigismo contratual, alterando profundamente o papel do Código Civil (TEPEDINO, 2000, p. 3-4). O fenômeno da descentralização tem início neste período e intensifica-se, no Brasil, a partir da década de 60, com a edição de diversos microssistemas jurídicos que criavam verdadeiro direito especial, destinando ao Código Civil a função de direito comum.

Com a ampliação dos microssistemas (i.e., centros de gravidade autônomos, do ponto de vista jurídico-positivo), o legislador deixa de atuar de maneira genérica e neutra diante de suportes fáticos considerados estruturas formais e abstratas, e passa a estimular a função promocional do Direito - característica do Estado Social, que incentiva comportamentos que atendam as prioridades traçadas (TEPEDINO, 2000, p. 5).

No âmbito do Direito Constitucional, ganha espaço a doutrina da máxima efetividade ou supremacia da Constituição, que propugna a centralidade do texto constitucional na interpretação do direito infraconstitucional - dando origem à consagrada interpretação conforme à Constituição. Como bem destaca Ingo Wolfgang Sarlet (2010, p. 14), os primeiros esforços para tratamento do tema no Brasil foram empreendidos por autores do Direito Privado a partir de uma perspectiva mais ampla de um Direito CivilConstitucional, ao tempo que a doutrina constitucionalista se dedicou mais às relaçóes entre os direitos fundamentais e o Direito Privado.

Este pensamento, no que concerne especificamente aos direitos fundamentais, lança profundos debates sobre a eficácia da norma constitucional, especialmente no que diz 
respeito aos direitos sociais e aos efeitos dos direitos fundamentais nas relaçóes privadas, o que pressupóe a efetividade da Constituição. Segundo Hesse (2009, p. 12), constituem pressupostos para a efetividade do sistema constitucional: (1) a sua consonância com as forças e tendências da realidade histórica em que está inserida e; (2) a disponibilidade dos dirigentes políticos e dos governados para aceitar como moralmente imperativo o conteúdo da Constituição.

Como decorrência de uma "constitucionalização do Direito Civil", que engendrou o que Fachin (2000, p. 317) denominou de "virada de Copérnico" no Direito Privado brasileiro, tem crescido o interesse da doutrina pátria no estudo da relaçáo entre direitos fundamentais e direito privado, em particular no que diz respeito à eficácia dos direitos fundamentais nas relaçôes privadas.

No Brasil, esses estudos têm base, especialmente, em doutrina e jurisprudência estrangeiras ${ }^{2}$, decorrentes de larga discussão jurisprudencial e de inúmeras publicações sobre o tema surgidas ao longo de três décadas no mundo inteiro, especialmente nos estudos formulados pelas doutrinas alemá, portuguesa, italiana e espanhola, bem como, mais recentemente, pela doutrina francesa e inglesa (CANARIS, 2009, p. 10), além da doutrina da state action norte-americana (SARLET, 2005, p. 198; SARMENTO, 2008, p. 193-196).

Na formulação de Sarlet (2005, p. 199), a questão da vinculação de particulares (pessoas físicas e jurídicas) aos direitos fundamentais orbita em torno de saber até que ponto pode o particular recorrer aos direitos fundamentais nas relaçóes com outros particulares, isto é, se, quando e de que modo poderá opor direito fundamental do qual é titular relativamente a outro particular, que, nesse caso, exerce o papel de destinatário (obrigado), mas que, por sua vez, também é titular de direitos fundamentais.

O tema da eficácia das normas definidoras de direitos fundamentais no âmbito das relaçóes jurídico-privadas acabou sendo versado, na doutrina e jurisprudência constitucionais, sob vários títulos, especialmente "eficácia privada", "eficácia em relação a terceiros" (Drittwirkung ou "eficácia externa") e "eficácia horizontal" dos direitos fundamentais (SARLET, 2005, p. 199), sendo este último o mais consagrado. Utilizaremos indistintamente todos eles, por não identificar nenhum elemento que justifique, no presente artigo, a distinção terminológica.

Nada obstante, a própria utilização do termo eficácia pode conduzir a certos equívocos e imprecisóes, o que é comum nas esferas doutrinária e jurisprudencial. Há quem distinga validade e eficácia, associando esta última, especificamente, à dimensão

2 O tema, ainda não pacificado no pensamento jurídico brasileiro, demanda um exame das peculiaridades do sistema jurídico pátrio, a justificar a aplicaçáo de uma ou de outra teoria da eficácia dos direitos fundamentais nas relaçóes privadas. 
processual do problema (SARLET, 2005, p. 201). Canaris (2009, p. 52), distinguindo validade (Geltung) e eficácia (Wirkung), afirma que o problema desta última se relaciona com os destinatários das normas de direitos fundamentais, o que difere dos efeitos dos direitos fundamentais sobre as normas de direito privado - o que Sarlet (2005, p. 202) chama de "vinculaçâo do legislador privado aos direitos fundamentais". Canaris (2009, p. 52) define a questão da seguinte forma:

Até agora falamos dos efeitos dos direitos fundamentais sobre as normas do direito privado e sobre sua aplicação e desenvolvimento. Em contrapartida, não tratamos, até o presente momento, da questão de saber se, e como, os sujeitos de direito privado se encontram, eles próprios, vinculados aos direitos fundamentais. Esta problemática - e, num correcto entendimento, apenas ela - é que constitui o objecto da discussão em torno da chamada "eficácia dos direitos fundamentais em relação a terceiros" (Drittwirkung).

Em sua clássica formulação sobre o pensamento sistemático na ciência do Direito, Canaris (2002) reconhece, igualmente, a importância dos direitos fundamentais na modificação do sistema objetivo como resultado não de uma intervenção direta do legislador (o que estaria de acordo com a doutrina tradicional das fontes do Direito), mas do postulado da unidade valorativa. Tal é a formulação do autor germânico (CANARIS, 2002, p. 114-115):

De acordo com a doutrina tradicional das fontes do Direito, deve partirse do princípio de que, em primeira linha, a modificação cabe ao legislador. Como exemplo, recorde-se mais uma vez o alargamento paulatino da responsabilidade pelo risco e a modificação do nosso sistema de Direito privado, com isso provocada. No entanto, não é sempre necessário verificar-se semelhante intervenção directa. As modificaçóes do sistema podem antes resultar de actos legislativos que respeitem, primeiramente, a domínios jurídicos inteiramente diferentes; nota-se, aqui, de modo particular, o postulado da unidade valorativa e, com isso, a força do pensamento sistemático. Um dos exemplos mais visíveis, que surge a tal propósito, é a doutrina da eficácia externa dos direitos fundamentais que só se torna compreensível sobre o pano de fundo da ideia da unidade da ordem jurídica e que, na forma da eficácia externa imediata ou mediata, modificou essencialmente o nosso sistema de Direito privado; o tema do Direito geral da personalidade torna-o particularmente claro.

$\mathrm{Na}$ doutrina brasileira, dentre as obras que tratam das teorias da eficácia imediata ou mediata dos direitos fundamentais nas relaçôes privadas ${ }^{3}$, prevalece a tese da vinculação

3 Sobre as teses da eficácia direta e indireta dos direitos fundamentais no âmbito do direito privado, cf. CANARIS, Claus-Wilhelm. Direitos Fundamentais e Direito Privado. 2. reimpressão. Coimbra: Almedina, 
direta dos particulares aos direitos constitucionais (SARMENTO, 2008, p. 260). A jurisprudência pátria ${ }^{4}$, outrossim, mesmo sem adentrar na discussão das teses jurídicas sobre a forma de vinculação dos particulares aos direitos fundamentais, vem aplicando diretamente os direitos fundamentais consagrados na Lei Maior na resolução de litígios privados (SARMENTO, 2008, p. 265) .

Nada obstante, mesmo sem fazer menção direta ao tema da eficácia horizontal dos direitos fundamentais, o Supremo Tribunal Federal, no julgamento da ADI n. ${ }^{\text {o } 319-4 /}$ DF, considerou constitucional a Lei federal n. ${ }^{\circ}$ 8.039/90, que limitava o reajuste de mensalidades em instituiçóes particulares de ensino de $1^{\circ}, 2^{\circ}$ e $3^{\circ}$ graus, com base na conciliação dos valores constitucionais da livre iniciativa do princípio da livre concorrência com os da defesa do consumidor e da redução das desigualdades sociais, em conformidade com os ditames da justiça social.

Tal posição parece aproximar-se bastante da teoria do dever estatal de proteção, que atribui ao legislador - e não ao juiz - a tarefa de conciliar autonomia privada e direitos fundamentais.

Ademais, a valorização do princípio da redução das desigualdades sociais (prevista no art. $3^{\circ}$, III, da Carta Magna), indica a tendência da Corte em proteger um dispositivo constitucional que os autores do campo do Direito Civil Constitucional costumam associar à ideia de igualdade substancial (TEPEDINO, 2003).

Perlingieri (2007, p. 44) destaca que o art. $3^{\circ}$ da Constituição italiana prevê a proteção integrada da igualdade formal (no parágrafo primeiro) e substancial (no parágrafo segundo), ressaltando que, na hipótese de contraste entre o princípio da igualdade (no nível constitucional) e o princípio da paridade de tratamento (no nível infraconstitucional), prevalece o primeiro. Isso porque quando existe desigualdade de fato, não existe espaço para o princípio da igualdade de tratamento (PERLINGIERI, 2007, p. 46).

Nada obstante, Perlingieri (2007, p. 49) acentua a impossibilidade do princípio da igualdade substancial se realizar em todo o seu alcance nas relaçóes privadas. A sua função

2009, p. 53-55; SARMENTO, Daniel. A vinculação dos particulares aos direitos fundamentais no direito comparado e no Brasil. In: Luís Roberto Barroso. (Org.). A nova interpretação constitucional: ponderação, direitos fundamentais e relaçôes privadas. Rio de Janeiro: Renovar, 3. ed. rev. Rio de Janeiro: Renovar, 2008, p. 210-244; MENDES, Gilmar Ferreira. Direitos fundamentais e controle de constitucionalidade: estudos de direito constitucional. 4. ed. São Paulo: Saraiva, 2012, p. 122-131.

4 Sobre a jurisprudência do STF na aplicação dos direitos fundamentais às relaçôes privadas, cf. MENDES, Gilmar Ferreira. Direitos fundamentais e controle de constitucionalidade: estudos de direito constitucional. 4. ed. São Paulo: Saraiva, 2012, p. 131-138.

5 O debate central, destarte, orbita em torno da definição da teoria a ser aplicada no direito brasileiro. Em geral, prevalece a doutrina da eficácia direta, mas há quem defenda a possibilidade do Ministério Público atuar na defesa de direitos fundamentais nas relaçóes entre particulares (CHEQUER, 2007), formulaçáo que não parece associar-se diretamente a esta teoria. 
seria contribuir, em sede interpretativa, para especificar o conteúdo que as cláusulas gerais devem assumir: da equidade à lealdade, do estado de necessidade à lesão e à causa não imputável, da diligência à boa-fé etc. A própria expropriação (equivalente à desapropriação no Brasil), na condição de aquisição coativa típica do direito administrativo, seria, segundo o autor italiano, uma técnica a serviço da justiça distributiva (igualdade substancial), começando a encontrar aplicaçóes no Direito Civil (Perlingieri, 2007, p. 53); esse pensamento parece encontrar eco no Direito Civil brasileiro, especialmente levando-se em consideração os $\$ \$ 3^{\circ}$ a $5^{\circ}$ do art. 1.228 do Código Civil.

Desta sorte, cumpre anotar que o Código Civil brasileiro apresenta alguns dispositivos que dizem respeito direto a direitos e garantias fundamentais, a exemplo dos $\$ \$$ $1^{\circ}$ a $5^{\circ}$ do art. 1.228, que mantém íntima conexão com a função social da propriedade, amparada por um conjunto de dispositivos constitucionais e, especialmente, pelo inciso XXIII do amplo catálogo de direitos fundamentais do art. $5^{\circ}$ da Magna Carta.

Vê-se, assim, que é possível detectar, no sistema jurídico brasileiro, a possibilidade de aplicação da teoria da eficácia mediata, que advoga a realização dos direitos fundamentais por intermédio de instrumentos próprios do direito privado, partindo da interpretação da Constituição como um conjunto de normas objetivas que estabelecem valores com eficácia irradiante.

Observe-se, ademais, que Perlingieri cita institutos similares àqueles encontrados no Código Civil brasileiro e que podem instrumentalizar a realização da igualdade substancial, a exemplo do estado de perigo (art. 156, CCB), da lesão (art. 157, CCB), que figuram como defeitos do negócio jurídico, bem como da boa-fé, cuja ausência, a despeito de não constituir motivo para a invalidade do negócio jurídico (tal qual prevê, v.g., o art. 51, IV, do Código de Defesa do Consumidor), revela-se critério interpretativo importante nas relaçóes negociais.

Ocorre que a aplicação direta de dispositivos constitucionais nas relaçôes privadas, quando dissociada de instrumentos próprios do Direito Civil, pode conduzir a situaçóes de arbítrio judicial, posto que é concedido essencialmente ao intérprete (notadamente o juiz) a tarefa da apurar a existência da desigualdade fática que demanda correção. Aí reside, corretamente, as críticas mais vigorosas contra o chamado Direito Civil Constitucional, inclusive no que diz respeito à proteção da igualdade nas relaçóes travadas sob a égide da autonomia privada.

\section{A Crítica ao Direito Civil Constitucional}

Decerto que a defesa da tese de extinção das diferenças entre Direito Público e Privado pode conduzir a um esvaziamento das normas de Direito Civil, tornando inócuas as 
tentativas de criar mecanismos de proteção da igualdade nas relaçóes particulares estruturadas a partir do legislador privado.

Em verdade, se a tônica das codificaçóes civis oitocentistas era a proteção da liberdade econômica, a projeção dos direitos fundamentais nas relaçóes privadas póe o holofote sobre o paradigma da igualdade nas relaçóes interprivadas, pois não se concebe mais, e.g., que um figurante de um negócio jurídico encontre-se em posição de desvantagem exagerada em relação ao outro. Tanto o Código Civil quanto o de Defesa do Consumidor já se ocuparam de traçar mecanismos e oferecer ferramentas jurídicas para evitar a desigualdade no negócio jurídico, no que se sobreleva a ideia de isonomia e equilíbrio contratual.

Doutra sorte, no Direito das Coisas, por exemplo, a propriedade, agora funcionalizada socialmente, cede espaço à dignidade da pessoa humana, podendo o possuidor, em diversos casos, preterir o proprietário se este se revela negligente em relação ao bem do que qual é dono. Assim, exempli gratia, o dono de um imóvel que não destina à sua propriedade (enquanto bem) a função social que lhe é inerente, vê o seu direito sucumbir diante do interesse daqueles que, não sendo proprietários de quaisquer outros imóveis urbanos ou rurais, ocuparam o bem negligenciado e nele passaram a residir (arts. $1.239 \mathrm{e}$ 1.240, CCB), o que demonstra, manifestamente, a intenção de preservar a moradia como instrumento de realização da dignidade humana.

Ocorre que os princípios da igualdade (no caso da ausência de equilíbrio contratual) ou da proteção da dignidade da pessoa humana (na hipótese de perda da propriedade por usucapião especial - arts. 1.239 e 1.240 do CCB - ou por desapropriação judicial privada - art. 1.228, $\$ \$ 4^{\circ}$ e $5^{\circ}$ do $C C B$ ) possuem mecanismos previstos na própria codificação para a sua implementação: pode-se falar, ilustrativamente, em invalidade do negócio jurídico por estado de perigo ou lesão (arts. 156 e 157, CCB), em revisão judicial do contrato por onerosidade excessiva ou pela aplicação da teoria da imprevisão (arts. 317 e 479, CCB).

Nos casos atinentes a defeitos do negócio jurídico ou a onerosidade excessiva, busca-se o equilíbrio contratual, o que denota, à evidência, a busca de um contrato justo, ao molde do modelo contemporâneo de contrato como vínculo de colaboração, que atende simultaneamente aos significados atuais de igualdade (substancial) e autonomia privada (BORGES, 2006, p. 34 e ss.).

Observe-se, bem assim, que o contrato não será anulado (art. 157, $\$ 2^{\circ}, \mathrm{CCB}$ ) nem se resolverá (art. 479, CCB) se for possível restabelecer o equilíbrio contratual. Deste modo, como assinala Laura Frantz (2014, p. 245), a seara contratual do Código Civil de 2002, permeada por novos princípios (boa-fé objetiva, função social e equilíbrio econômico), convive em absoluta harmonia com os princípios contratuais clássicos, como a autonomia privada e a força vinculante dos pactos, tendo o Diploma Cível, neste particular, 
utilizado a revisão do art. 317 e a resolução do art. 478 como soluções para a onerosidade excessiva.

Destarte, mesmo reconhecendo a necessidade de se proceder a uma interpretação do Direito Civil conforme à Constituição, a tese defendida por alguns autores como Paulo Lôbo (2008, p. 19) de que o centro do Direito Civil foi deslocado para a Constituição pode conduzir ao esvaziamento do Direito Privado, por não competir à Lei Maior a oferta de instrumentos mais específicos de defesa dos particulares em situaçóes de desigualdade.

Faz-se necessário, portanto, delimitar o campo de atuação do Direito Civil atual no Brasil (o seu proprium), o que pode ser feito a partir de diferentes caminhos: das grandes teorias sobre a sociedade em geral, da ordem constitucional ou da doutrina do Direito Privado (GRUNDMANN, 2014, p. 234). Neste particular, a escolha pela doutrina do Direito Privado (e, em especial, do Direito Civil) impóe a identificação dos instrumentos privatísticos que se mostram compatíveis com a realização de princípios como igualdade (substancial) e dignidade da pessoa humana ${ }^{6}$.

Otávio Luiz Rodrigues Junior (2011), tecendo vigorosa crítica, afirma que, no Brasil, as contestaçóes à tradição da civil law e do Direito Civil - hoje maiores do que nunca - são baseadas em novos movimentos como o neoconstitucionalismo, a crítica à teoria da separação de poderes e o ativismo judicial. Além disso, de forma mais ampla, outros movimentos como o realismo jurídico, o Law and Economics e as teorias da argumentação também seriam responsáveis pela derruição do sistema do direito privado.

Neste sentido, boa parte das críticas é direcionada ao sincretismo metodológico, que associa, e.g., sem rigor, ferramentas da análise econômica do Direito e a ponderaçáo de princípios ou valores (VILLELA, 2009; STRECK, 2011; GARCIA AMADO, 2007; JUNQUEIRA DE AZEVEDO, 2008).

Segundo Rodrigues Junior, seria grande equívoco afirmar que o Direito Civil clássico e a tradição de civil law nele baseada são contrários a valores; estes consubstanciariam, mesmo no pensamento de Kelsen, critérios para a análise externa do direito, tal qual a ideia de eficiência contida na análise baseada em ferramentas da Law and Economics. A análise externa de fatos e valores, malgrado reconhecida pelo autor da teoria pura, náo seria, na formulação do pensador tcheco, objeto da ciência jurídica, que se preocuparia unicamente com elementos constantes da análise interna do direito ${ }^{7}$.

6 Antonio Junqueira de Azevedo (2002, p. 100), por exemplo, identifica que a dignidade da pessoa humana como princípio jurídico pressupoo o imperativo categórico da intangibilidade da vida humana, dando origem, em sequência hierárquica, aos seguintes preceitos: 1) respeito à integridade física e psíquica das pessoas; 2) consideração pelos pressupostos materiais mínimos para o exercício da vida; e 3) respeito às condições mínimas de liberdade e convivência social igualitária.

7 Rodrigues Junior (2011, p. 48-9) adverte que não está, necessariamente, a defender o positivismo kelseniano, mas apenas a demonstrar que os fatos e valores já eram elementos cuja importância não se 
Assim, mesmo no pensamento kelseniano, uma análise interna do art. 765 do CCB (que dispóe que segurado e o segurador são obrigados a conservar, no aperfeiçoamento e na execução do contrato, a mais estrita boa-fé e veracidade, tanto a respeito do objeto como das circunstâncias e declaraçôes a ele concernentes) pressupóe desconsiderar, na interpretação da norma, elementos sociológicos, econômicos ou de caráter exclusivamente moral. Ainda assim, existe um espaço de indeterminação interpretativa que constitui a moldura, indeterminação esta acentuada em virtude da presença de conceitos jurídicos indeterminados e cláusulas gerais (boa-fé e probidade/veracidade) (RODRIGUES JUNIOR, 2011, p. 49).

O mesmo art. 765, contudo, poderia ser objeto de uma análise externa, baseada, por exemplo, na análise econômica do direito, onde a justiça seria substituída pelo critério da eficiência (RODRIGUES JUNIOR, 2011, p. 50), o que parece ser uma crítica bem percuciente, especialmente observando que a ideia de equilíbrio contratual geralmente pressupóe a ideia de equivalência material (é dizer, economicamente paritárias) de prestações.

Da mesma forma, uma análise externa baseada no instrumental do Law and Economics sobre a doutrina do terceiro cúmplice (RODRIGUES JUNIOR, 2004) conduziria à avaliação sobre os efeitos nocivos ou não da responsabilização do terceiro que interfere ilicitamente em relaçóes negociais alheias, induzindo sua ruptura ou gerando danos aos contraentes. É perquirir: seria de todo ruim essa atuação ou ela é um mecanismo interessante de fomento às relaçóes entre agentes no mundo produtivo? A resposta a essa questão conduz, invariavelmente, a um critério econômico de análise, que se revela necessariamente externo (RODRIGUES JUNIOR, 2011, p. 50).

Outra crítica poderosa direciona-se às decisóes marcadas pelo que o autor denomina de sindrome de Sherwood, pois "os contratos de Direito Civil, em tese paritários, seriam o âmbito ideal para que os juízes se convertam em Robin dos Bosques e tirem dos ricos para dar aos pobres" (RODRIGUES JUNIOR, 2011, p. 56). Este seria o móvel para a intervenção judicial nos contratos. Os problemas essenciais daí decorrentes, diz o autor, são o esvaziamento politico do espaço democrático e a criação de um campo fértil para a açáo dos interessados no arbítrio e no abuso da discricionariedade judicial ${ }^{8}$.

ignorava, mesmo no pensamento formal de Kelsen, o que conduz à possibilidade de se tomar o Direito (ou o fenômeno jurídico) sobre duas perspectivas: uma interna (elementos próprios da ciência jurídica) e outra externa (elementos distintos - porém conexos - da ciência jurídica).

8 Para que se faça justiça à formulação de Rodrigues Junior e não se deixe entender que este defende o retorno ao Direito Civil Oitocentista, cumpre transcrever trecho final do seu artigo, que descreve com nitidez o ponto central da sua crítica:

"Antes que se tente confundir as teses aqui defendidas com um 'canto do cisne' do Direito Civil Oitocentista ou com um apelo no estilo de Juliano, o Apóstata, de retomada da religião pagã, é preciso registrar que não se desconhece a incompetência do Direito Privado (e de seus estudiosos) em 
Portanto, parece lícito afirmar ser necessário reconhecer os avanços e os excessos do Direito Civil Constitucional, de modo a possibilitar um estudo que aceite a tangibilidade do Direito Civil sem, contudo, esvaziá-lo. Neste sentido, cabe apontar, de forma breve e ilustrativa, algumas figuras presente na codificação civil brasileira que, associadas à autonomia privada, demonstram-se compatíveis ou não com a ideia de igualdade substancial.

\section{Alguns Instrumentos Normativos de Concretização do Princípio da Igual- dade Substancial Presentes no Código Civil Brasileiro de 2002}

Parece lícito reconhecer que o Código Civil brasileiro de 2002 traz instrumentos idôneos à concretização do princípio da igualdade substancial, plenamente compatíveis com o princípio clássico da autonomia privada. Ilustrativamente, cumpre tecer uma breve leitura do erro, do estado de perigo e da lesão ${ }^{9}$, ligadas que estão, diretamente, à autonomia privada.

compreender as transformaçóes sociais e não oferecer mecanismos de adaptação aos novos tempos, por meio de novos institutos jurídico-privados. Foi essa miopia que permitiu o surgimento do Direito do Trabalho (a partir dos contratos de locação de mão de obra), do Direito do Consumidor (sob a base contratual civilística) e das leis de locação predial urbana.

Não se ignora que as relaçôes no mundo privado são marcadas, em diversos casos, pela assimetria entre as partes. O fenômeno da vulnerabilidade de diversos agentes é inegável e eles não podem ser deixados entregues à própria sorte, como se a 'mão invisível' do mercado tudo fosse capaz de resolver. Os grandes grupos econômicos podem ser tấo nocivos aos privados quanto o Estado, em muitas situaçóes. No reconhecimento da entropia do mundo privado, não se deseja o retorno aos tempos de 1929. A tragédia da crise econômica de 2008 é uma prova de que a atuação regulatória (e portanto ex ante) foi ineficaz, o que deu margem a diversos questionamentos judiciais, que levarão para o campo da indeterminação. A autonomia privada não se ressente da regulação ex ante. Ela é mais do que necessária, porque define as regras do jogo, antes de seu início.

A posição aqui sustentada diz respeito a problemas de caráter epistemológico, da falta de rigor e de coerência no desempenho do papel (essencial) dos doutrinadores e na renúncia às soluçóes dos problemas jurídicos com base em respostas que o Direito Privado pode e tem condiçóes de oferecer. O risco está, ainda, no que advertiu Konrad Hesse, citando Alexis de Tocqueville, na perda da capacidade humana de 'configuraçấo responsável e autônoma da própria vida', não por um Estado todo-poderoso e ditatorial, mas pelo Estado excessivamente protetivo, que acostuma os homens com sua máo bondosa, quando, na verdade, os escraviza em uma gaiola de ouro.

Em Portugal ou na Alemanha, para se ficar com esses dois exemplos, muitos avanços na tentativa de adaptar a tradição de civil law e o Direito Civil clássico às exigências de nosso tempo foram obtidos, apesar de alguns embaraços, sem que, para isso, se fizesse necessário abandonar dois mil anos de experiência jurídica sem qualquer vantagem para o Direito ou a sociedade. Muitas das questóes relativas ao Direito Civil, aqui expostas, são comuns ao Direito Constitucional, no que se refere ao abandono dos fóruns de deliberação democrática, da perda da dignidade da legislação e da busca pelo Santo Graal da judicialização de políticas públicas e de agendas morais, que deveriam ser implementadas ou decididas nas esferas adequadas e legítimas. Nesse ponto, os dois elementos da tradição de civil law unem-se nas mesmas adversidades." (RODRIGUES JUNIOR, 2011, p. 65-6)

9 Poder-se-ia tratar, no mesmo sentido, da teoria da imprevisão e da resolução por onerosidade excessiva, o que demandaria uma análise mais complexa, que excederia os limites do presente paper e que constituem 
Ressalte-se que o presente artigo não tem a pretensão de esgotar o estudo destas três figuras, mas apenas indicar a sua compatibilidade ou não com a ideia de igualdade substancial. Poder-se-ia, certamente, analisar outros institutos sob esta mesma perspectivas, mas isso constitui uma proposta maior.

No que alude ao erro como defeito do negócio jurídico (arts. 138 e ss.), vê-se que o Código atual previu que somente seria considerado vício que contamina a liberdade da vontade aquele substancial e escusável. Erro desculpável, para o Código, é aquele que não seria cometido por pessoa de diligência normal. Em outras palavras, erro invalidante é aquele perdoável, que não seria cometido pelo homem médio.

O problema reside exatamente em determinar o que seria homem médio. No conceito clássico do Direito Civil, o termo nos conduziria intuitivamente à ideia de pessoa que pratica habitualmente atos de comércio jurídico, ou, de outra forma, possui instruçáo formal suficiente para detectar a necessidade de uma diligência em um negócio jurídico eventual que venha a realizar. Nada obstante, essa definição despreza a eventual desigualdade fática, que pode residir na deficiência de instrução formal, na pouca experiência (o que se aproxima da inexperiência possível na lesão), na diferença socioeconômica, na dificuldade de acesso a órgãos ou repartiçôes públicas etc.

Tome-se o seguinte exemplo: um contrato de compra e venda de bem imóvel de valor superior a trinta salários mínimos, celebrado por instrumento particular por pessoa pobre e que desconhece a necessidade do ato registral para transferência dominial, configura, legalmente, causa de nulidade do negócio jurídico. Tratando-se de invalidade formal, a repetição do ato pela forma adequada (instrumento público associado ao registro no cartório de imóveis) removeria o problema, tal qual indica Marcos Bernardes de Mello (2014, p. 111).

Ocorre que tal negócio pode ser praticado em zonas urbanas periféricas de grandes cidades onde se tem habitaçóes desordenadas e desprovidas de registro imobiliário, o mesmo acontecendo em pequenas cidades onde a população não tem o hábito de dirigir-se ao tabelionato de notas para lavrar escrituras públicas, celebrando atos cotidianos de disposição de bens imóveis sem a forma adequada e desprovido do regular registro imobiliário. Veja-se que, a rigor, não apenas o negócio seria nulo, como também sequer constituiria, eventualmente, justo título para efeito de usucapião ordinária, posto carente de transcrição no cartório de imóveis.

matéria suficiente para outro artigo, específico, sobre a temática. Para uma leitura mais acurada da teoria da imprevisão e, inclusive, da sua afinidade com as figuras do erro, lesão e estado de perigo (analisadas brevemente no presente trabalho), remete-se o leitor à apreciação da obra de Otávio Luiz Rodrigues Junior, "Revisão Judicial dos Contratos: Autonomia da Vontade e Teoria da Imprevisáo", que faz uma análise cuidadosamente consistente do tema. 
É certo que a doutrina e a jurisprudência cuidam de abrandar a necessidade de registro, como se vê da Súmula n. ${ }^{\circ} 84^{10}$ do STJ e do Enunciado de n. ${ }^{\circ} 86^{11}$ da I Jornada de Direito Civil (promovida pelo STJ em conjunto com o Conselho da Justiça Federal), mas parece evidente que a ideia de homem médio, que resgata a figura do pater bonus familiae, revela-se manifestamente anacrônica, considerando as substanciais diferenças socioeconômicas possíveis entre os contraentes de negócios de disposição de bens imóveis.

Veja-se que a doutrina, atualmente, controverte acerca do critério da escusabilidade para aferição do erro: para um setor relevante, erro invalidante é aquele reconhecível pela outra parte, ainda que grosseiro (e, portanto, inescusável). Ocorre que esse entendimento, consubstanciado no Enunciado n. ${ }^{\circ} 12^{12}$ da I Jornada de Direito Civil, malgrado possua o condão de valorizar o princípio da confiança (como dever anexo decorrente da boa-fé objetiva), induz demasiada aproximação da figura do dolo (ou erro provocado), esvaziando (ainda mais) o instituto do erro ${ }^{13}$.

Doutra ponta, louvável a inclusão, no novo Código Civil, dos institutos do estado de perigo (art. 156) e da lesáo (art. 157), tendentes a equacionar a onerosidade excessiva ou a desproporcionalidade material das prestaçôes. Parece evidente que ambos são vocacionados a combater o desequilíbrio na relação negocial, tornando anuláveis atos de vontade em que se verifique a desigualdade material entre os contraentes. Sucede que, nestas figuras, pouco importa a condiçáo pessoal do contraente: importa saber se há onerosidade excessiva imposta a alguma das partes.

Veja-se que, ainda que esteja localizado no plano de validade do negócio jurídico, induzindo a sua anulabilidade, os vícios consubstanciados no estado de perigo ou na lesáo deverão prioritariamente ser sanados por meio da revisão judicial do contrato, conforme proclama o art. $157, \$ 2^{\circ}$, do CCB e os enunciados n. ${ }^{0} 148^{14}$ e $149^{15}$ das Jornadas de Direito Civil, sempre privilegiando o que se convencionou chamar de princípio da conservação ou manutençâa do contrato.

Decerto que o estado de perigo e a lesão diferem da teoria da imprevisão (art. 317, no que diz respeito às obrigaçôes pecuniárias, e 478 e ss., no que alude às obrigaçóes em

10 "É admissível a oposição de embargos de terceiro fundados em alegação de posse advinda do compromisso de compra e venda de imóvel, ainda que desprovido do registro."

11 “Art. 1.242: A expressão ‘justo título’ contida nos arts. 1.242 e 1.260 do Código Civil abrange todo e qualquer ato jurídico hábil, em tese, a transferir a propriedade, independentemente de registro."

12 "Art. 138: Na sistemática do art. 138, é irrelevante ser ou náo escusável o erro, porque o dispositivo adota o princípio da confiança."

13 Do ponto de vista prático, raras são as açóes anulatórias fundadas no erro, especialmente pela dificuldade probatória da sua espontaneidade.

14 “Art. 156: Ao 'estado de perigo' (art. 156) aplica-se, por analogia, o disposto no $\$ 2$ o do art. 157."

15 "Art. 157: Em atençẫo ao princípio da conservação dos contratos, a verificação da lesão deverá conduzir, sempre que possível, à revisão judicial do negócio jurídico e não à sua anulação, sendo dever do magistrado incitar os contratantes a seguir as regras do art. 157, \$2o, do Código Civil de 2002." 
geral) em razão de serem apreciados no momento da celebração do negócio jurídico. Daí porque são vícios de consentimento e consubstanciam hipóteses de anulabilidade do ato.

Nada obstante, a aplicação do princípio da preservação dos contratos culmina por aproximar em demasia os aludidos defeitos do negócio jurídico em relação à teoria da imprevisão, especialmente se considerarmos que a doutrina, atualmente, nas relaçóes não consumeristas, entende prescindível a imprevisibilidade quando se tratar de onerosidade excessiva superveniente (BORGES, 2006, p. 41-2), nos mesmos moldes do que prevê o Código de Defesa do Consumidor.

Veja-se, neste particular, que tanto em um caso (estado de perigo ou lesão como vícios invalidantes) como em outro (seja a onerosidade excessiva do art. 317, seja a manutenção do contrato com base no art. 479) prioriza-se a revisão judicial.

Em ambos, contudo, verifica-se a predominância de um critério econômico (ainda que não metodologicamente estruturado) para solução do problema: a promoção do reequilíbrio contratual por intermédio da recomposição da paridade de prestaçóes.

Evidencia-se, deste modo, uma análise externa do problema, mas, no caso da lesão e do estado de perigo, o critério manejado para solução parte, eminentemente, de uma análise interna do fenômeno jurídico: o Código Civil aponta expressamente a oferta do suplemento suficiente como instrumento para reequilibrar o negócio jurídico (cf. art. $\left.157, \$ 2^{\circ}, \mathrm{CCB}\right)$.

Já na segunda hipótese, abre-se espaço à interpretação judicial, que, se mal empregada, pode dar azo à inversão da desproporção (justificada, por exemplo, na grande diferença socioeconômica entre os contraentes), o que antes mantém o problema do que o soluciona. É o que se depreende da leitura do enunciado n. $367^{16}$ das Jornadas de Direito Civil, que parece pressupor que, caso assegurado o contraditório, garantir-se-á, automaticamente, a justiça contratual. Tratando-se de prestaçóes materiais, parece lógico inferir que a simples oitiva da outra parte (garantia fundamental do direito fundamental à igualdade) não assegura a recomposição justa do contrato.

Evidencia-se, neste particular, o risco de ofensa à segurança jurídica e à própria igualdade, decorrente da utilização indiscriminada e isolada, e.g., de diretrizes constitucionais como dignidade da pessoa humana, apartadas de critérios como hipossuficiência e vulnerabilidade, próprios do direito privado, resultando em uma aplicação imotivada de princípios constitucionais em absoluto abandono de instrumentos idôneos do Direito Civil.

Por fim, releva notar que o Código Civil parece indicar, mesmo timidamente, que a ideia de igualdade substancial parece funcionar, efetivamente, como limite à autonomia

16 "Art. 479: Em observância ao princípio da conservação do contrato, nas ações que tenham por objeto a resolução do pacto por excessiva onerosidade, pode o juiz modificá-lo eqüitativamente, desde que ouvida a parte autora, respeitada sua vontade e observado o contraditório.” 
privada: presente a desproporção de prestaçóes, a ignorância ou inexperiência do contraente, por exemplo, restabelece-se o equilíbrio negocial, resolve-se ou anula-se o negócio.

Em outras palavras: verificando-se vício na formação da vontade (defeitos do negócio jurídico) ou onerosidade excessiva (lesão objetiva), não há que se falar em cumprimento coativo do contrato. O princípio da vinculação do contrato será observado, contudo, tão logo se reestruture o equilíbrio econômico contratual, preservando, assim, a autonomia privada manifestada pelas partes negociantes.

\section{Conclusões}

A dualidade público-privado, estruturante no pensamento jurídico, vem sofrendo grande abalo, especialmente no último período histórico, em razão do fenômeno denominado constitucionalização do direito, que enfraqueceu as fronteiras (há muito criticadas) entre Direito Público e Direito Privado.

Neste compasso, tomou corpo na doutrina civilista o campo teórico que se autodenominou Direito Civil Constitucional, que, malgrado tenha trazido contribuiçóes essenciais ao pensamento privatístico, pondo termo à pretensa intangibilidade do Direito Civil por outros setores do Direito (especialmente o Constitucional), culminou por valorizar em demasia o aludido fenômeno, convertendo a benéfica constitucionalização na maléfica colonização do Direito Civil pelo Direito Constitucional.

Desta maneira, se o Direito Civil Constitucional ostenta o mérito de ter retirado do isolamento e do idealismo jurídico a doutrina civilista, trouxe como efeito nocivo o abandono dos institutos próprios do Direito Civil.

A afirmaçáo corrente do suposto fim da dicotomia público-privado traz como resultado prático o abandono do estudo criterioso e da aplicação das ferramentas oferecidas pelo Código Civil para a solução dos problemas próprios das relaçóes privadas. Em ultima ratio, isso pode significar o não investimento em lutas democráticas pela positivação, no Código Civil ou em legislação especial, de outros instrumentos jurídicos aptos a concretizar direitos fundamentais (considerando que todo direito e garantia fundamental é conquistado, e não concedido).

Se é certo que o Direito Civil oitocentista era insensível aos ditames da igualdade substancial, valorizando em excesso uma igualdade formal favorável à manutenção de privilégios, o Direito Civil, no período contemporâneo, parece estar mais atento aos reclamos de igualdade, ainda que não na velocidade desejada (especialmente ao se tratar de codificaçóes).

Assim, mesmo reconhecendo a necessidade de se proceder a uma interpretação do Direito Civil conforme à Constituição, a tese defendida por alguns autores de que o centro 
do Direito Civil foi deslocado para a Constituição pode conduzir ao esvaziamento do Direito Privado, por não competir à Lei Maior a oferta de instrumentos mais específicos de defesa dos particulares em situaçóes de desigualdade.

Faz-se necessário, portanto, delimitar o campo de atuação do Direito Civil atual no Brasil (o seu proprium), o que pode ser feito a partir de diferentes caminhos: das grandes teorias sobre a sociedade em geral, da ordem constitucional ou da doutrina do Direito Privado. Neste particular, a escolha pela doutrina do Direito Privado - e, em especial, do Direito Civil - impóe a identificação dos instrumentos privatísticos que se mostram compatíveis com a realização de princípios como igualdade e dignidade da pessoa humana.

Destarte, situado historicamente em um período de afirmação de direitos prestacionais e construído com base em diretrizes distintas da codificação brasileira de 1916, o novo Diploma Civil pátrio apresenta, mesmo que de forma insuficiente, instrumentos idôneos à concretização da aludida igualdade, que se encontram frequentemente esquecidos por correntes doutrinárias em virtude da valorização excessiva do fenômeno chamado constitucionalização do direito. $\mathrm{O}$ avanço tímido do Código Civil em direção à igualdade substancial não justifica, contudo, o abandono do Direito Civil, devendo-se resgatar o estudo criterioso e a instrumentalização das ferramentas postas à disposição pela codificação para a concretização da igualdade material.

Por fim, releva notar que o Código Civil parece indicar, mesmo timidamente, que a ideia de igualdade substancial funciona como efetivo limite à autonomia privada: presente a desproporção de prestações, a ignorância ou inexperiência do contraente, por exemplo, restabelece-se o equilíbrio negocial, resolve-se ou anula-se o negócio. Em outras palavras: verificando-se vício na formação da vontade (defeitos do negócio jurídico) ou onerosidade excessiva (lesão objetiva), não há que se falar em cumprimento coativo do contrato. O princípio da vinculação do contrato será observado, contudo, tão logo se reestruture o equilíbrio econômico contratual, preservando, assim, a autonomia privada manifestada pelas partes negociantes.

\section{Referências}

AMARAL NETO, Francisco dos Santos. Autonomia Privada. Revista CEJ. Brasília: CEJ, v. 3, n. 9, p. 25-31, set./dez. 1999.

ASSOCIAÇÃO BRASILEIRA DE NORMAS TÉCNICAS. NBR n. 6023 - ago. 2002. Informação e documentação - Referências - Elaboração. Rio de Janeiro: ABNT, 2002.

ASSOCIAÇÃO BRASILEIRA DE NORMAS TÉCNICAS. NBR n. 6024 - mai. 2003. Informação e documentação - Numeração progressiva das seçôes de um documento escrito - Apresentação. Rio de Janeiro: ABNT, 2003. 
ASSOCIAÇÃO BRASILEIRA DE NORMAS TÉCNICAS. NBR n. 14724 - mar. 2011. 3. Ed. Informação e documentação - Tratados acadêmicos - Apresentação. Rio de Janeiro: ABNT, 2011.

BARROSO, Luís Roberto. Curso de Direito Constitucional Contemporâneo: os conceitos fundamentais e a construção do novo modelo. 2. ed., 2. tiragem. São Paulo: Saraiva, 2011.

BOBBIO, Norberto. Estado, governo, sociedade: por uma teoria geral da política. São Paulo: Paz e Terra, 2011.

BODIN DE MORAES, Maria Celina. A Caminho de um Direito Civil Constitucional. Direito, Estado e Sociedade. Rio de Janeiro, v. 1, p. 59-73, 1991.

BORGES, Roxana Cardoso Brasileiro. Contrato: do clássico ao contemporâneo - a reconstrução do conceito. Revista do Programa de Pós-Graduação em Direito da UFBA, n. 13, p. 29-50, 2006.

Disponibilidade dos direitos de personalidade e autonomia privada. Sáo Paulo: Saraiva, 2005.

CANARIS, Claus-Wilhelm. Direitos Fundamentais e Direito Privado. 2. reimpressão. Coimbra: Almedina, 2009

Pensamento sistemático e conceito de sistema na ciência do direito. 3. ed. Lisboa: Fundação Calouste Gulbenkian, 2002.

FACHIN, Luiz Edson (Org.). Repensando fundamentos do Direito Civil brasileiro contemporâneo. Rio de Janeiro: Renovar, 2000.

FACCHINI NETO, Eugênio. Reflexóes histórico-evolutivas sobre a constitucionalização do direito privado. In: SARLET, Ingo Wolfgang (org.). Constituiçáo, Direitos Fundamentais e Direito Privado. 3. ed. rev. e ampl. Porto Alegre: Livraria do Advogado Editora, 2010, p. 37-75.

FERRI, Luigi. La Autonomía Privada. Granada: Comares, 2001.

FRANTZ, Laura Coradini. Excessiva Onerosidade Superveniente: análise dos julgados do STJ. In: Judith Martins-Costa (org.). Modelos de Direito Privado. 1. ed. São Paulo: Marcial Pons, 2014, p. 215-248.

GARCÍA AMADO, Juan Antonio. Derechos y pretextos. Elementos de crítica del neoconstitucionalismo. In: CARBONELL, Miguel (org). Teoría del neoconstitucionalismo: ensayos escogidos. Madrid: Trotta, 2007. p. 237-264.

GRUNDMANN, Stefan. Qual a unidade do direito privado? De uma concepção formal a uma concepção material do direito privado. In: GRUNDMANN, Stefan; MENDES, Gilmar; MARQUES, Cláudia Lima; BALDUS, Christian; MALHEIROS, 
Manuel (Orgs.). Direito Privado, Constituiçáo e Fronteiras: encontros da Associação Luso-Alemã de Juristas no Brasil. 2. ed. rev. e ampl. São Paulo: Revista dos Tribunais, 2014, p. 233-261.

HESSE, Konrad. Constituição e Direitos Constitucionais. In: HESSE, Konrad. Temas fundamentais do direito constitucional. São Paulo: Saraiva, 2009, p. 1-22.

JUNQUEIRA DE AZEVEDO, Antonio. Caracterização jurídica da dignidade da pessoa humana. Revista USP. São Paulo, n. 53, p. 90-101, mar./mai. 2002.

. O direito ontem e hoje: crítica ao neopositivismo constitucional e à insuficiência dos direitos humanos. Revista do Advogado, v. 28, n. 99, p. 7-14, set. 2008.

LÔBO, Paulo. A Constitucionalização do Direito Civil brasileiro. In: TEPEDINO, Gustavo (org.). Direito Civil Contemporâneo: novos problemas à luz da legalidade constitucional. São Paulo: Atlas, 2008, p. 18-28.

MELLO, Marcos Bernardes de. Teoria do Fato Jurídico: plano da validade. 13. ed. São Paulo: Saraiva, 2014.

MENDES, Gilmar Ferreira. Direitos fundamentais e controle de constitucionalidade: estudos de direito constitucional. 4. ed. São Paulo: Saraiva, 2012.

PERLINGIERI, Pietro. Perfis do Direito Civil: introdução ao Direito Civil Constitucional. 3. ed. Rio de Janeiro: Renovar, 2007.

PRATA, Ana. Dicionário Jurídico. 3. ed. rev. e atual. Coimbra: Almedina, 1998.

RODRIGUES JUNIOR, Otávio Luiz. A doutrina do terceiro cúmplice: autonomia da vontade, o princípio res inter alios acta, função social do contrato e a interferência alheia na execução dos negócios jurídicos. Revista dos Tribunais, v. 93, n. 821, p. 80-98, mar. 2004.

. Estatuto epistemológico do Direito Civil Contemporâneo na tradição de Civil Law em face do neoconstitucionalismo e dos princípios. O Direito, n. 143, II, p. 43-66, 2011.

. Revisáo Judicial dos Contratos: autonomia da vontade e teoria da imprevisão. 2. ed. rev., ampl. e atual. São Paulo: Atlas, 2006.

SARLET, Ingo Wolfgang (Org.). Direitos fundamentais e direito privado: algumas consideraçóes em torno da vinculação dos particulares aos direitos fundamentais. In: Boletim Científico. Escola Superior do Ministério Público da União. Brasília: ano 4, n. 16, p. 193-259, jul./set. 2005.

. Neoconstitucionalismo e influência dos direitos fundamentais no direito privado: algumas notas sobre a evolução brasileira. In: SARLET, Ingo Wolfgang (org.). 
Constituição, Direitos Fundamentais e Direito Privado. 3. ed. rev. e ampl. Porto Alegre: Livraria do Advogado Editora, 2010, p. 13-36.

SARMENTO, Daniel. A vinculação dos particulares aos direitos fundamentais no direito comparado e no Brasil. In: Luís Roberto Barroso. (Org.). A nova interpretaçáo constitucional: ponderação, direitos fundamentais e relaçóes privadas. Rio de Janeiro: Renovar, 3. ed. rev. Rio de Janeiro: Renovar, 2008, p. 193-284.

. Direitos Fundamentais e Relaçóes Privadas. 2. ed., 2. tiragem. Rio de Janeiro: Lumen Juris, 2008.

(org.). Interesses públicos versus interesses privados: descontruindo o princípio da supremacia do interesse público. 3. tiragem. Rio de Janeiro: Lumen Juris, 2010.

STRECK, Lenio Luiz. Verdade e consenso: constituição, hermenêutica e teorias discursivas. 4. ed. São Paulo: Saraiva, 2011.

TEPEDINO, Gustavo. O Código Civil, os chamados microssistemas e a Constituição: premissas para uma reforma legislativa. In: TEPEDINO, Gustavo (coord.). Problemas de Direito Civil-Constitucional. Rio de Janeiro: Renovar, 2000, p. 1-16. - Crise das Fontes Normativas e Técnica Legislativa na Parte Geral do Código Civil de 2002. In: TEPEDINO, Gustavo (coord.). A Parte Geral do Novo Código Civil: estudos na perspectiva civil-constitucional. Rio de Janeiro: Renovar, 2002.

VILLELA, João Baptista. Variaçôes impopulares sobre a dignidade da pessoa humana. Superior Tribunal de Justiça: Doutrina. Edição comemorativa, 20 anos, Distrito Federal, 2009. p. 559-581. 